\title{
ATIVIDADE MICROBIANA EM SOLOS ARENOSOS, SOB DIFERENTES MANEJOS AGRÍCOLAS
}

Bruna Oliveira Spolaor, Alana Andrade, Ester Gerônimo Serra, Débora Cristina Rodrigues, Matheus

Venâncio Prado, Fabio Fernando Araujo, Luciana Machado Guaberto.

Universidade do Oeste Paulista - UNOESTE, curso de Agronomia, Presidente Prudente, SP. E-mail: brunaspolaor@hotmail.com

\section{RESUMO}

O objetivo do trabalho foi avaliar a atividade microbiana de solos, pela quantificação do número de bactérias aeróbicas, respiração, extração de DNA e atividade enzimática (desidrogenase). As amostras de solo foram coletadas aleatoriamente dentro de áreas agrícolas do Campus II da Universidade do Oeste Paulista, sendo elas: horta, viveiro de plantas, mata reflorestada, áreas de cultivos de milho, café, cana-de-açúcar e citros. Foram coletadas três sub amostras de cada local na camada de $0-20 \mathrm{~cm}$ do solo. A realização das análises microbianas foram conduzidas em laboratório da própria Universidade. Os resultados mostraram que o solo oriundo da horta e do viveiro obtiveram os melhores desempenhos comparados com as áreas cultivadas com cana-deaçúcar e citros. No entanto o solo da mata, de cultivos de milho e café obtiveram valores intermediários. Os indicadores microbianos encontrados na horta e no viveiro sugerem que nesses locais houve melhores práticas de manejo do solo.

Palavras-chave: Microbiologia, Desidrogenase, DNA, Respiração e Solo.

\section{MICROBIAL ACTIVITY IN SANDY SOILS, UNDER DIFFERENT AGRICULTURAL MANAGEMENT}

\begin{abstract}
The objective of this study was to evaluate the microbial activity of soils by quantifying the number of aerobic bacteria, respiration, DNA extraction and enzymatic activity (dehydrogenase). Soil samples were randomly collected within the agricultural areas of Campus II at Universidade do Oeste Paulista. These were: vegetable garden, plant nursery, reforested forest, maize, coffee, sugarcane and citrus growing areas. Three sub samples of each site were collected in the $0-20 \mathrm{~cm}$ layer of the soil. The microbial analyzes were carried out in the laboratory of the University. The results showed that the soil from the garden and the nursery had the best performance compared to the areas cultivated with sugarcane and citrus. However, the soil of the forest, corn and coffee plantations obtained intermediate values. The microbial indicators found in the orchard and in the nursery suggest that in these places there were better practices of soil management.
\end{abstract}

Keywords: Microbiology, Dehydrogenase, DNA, Breath and Soil. 


\section{INTRODUÇÃO}

O estudo da microbiologia agrícola vem crescendo cada vez mais, com o intuito de aumentar a produtividade nas culturas agrícolas, atuando de forma sustentável e mantendo funções vitais para a saúde do solo, através das atividades microbiológicas na terra. Porém, mesmo que haja diversos avanços científicos na conservação da vida do solo, pouco desses conhecimentos vem sendo investido nas práticas agronômicas (ARAÚJO; HUNGRIA, 1994, p. 3). Esta falta de conservação para com os agentes decompositores acarretando em grandes retrocessos na agricultura, pois, esses microrganismos juntamente com outros agentes biológicos são considerados indicadores de qualidade, decompositores de matéria orgânica e fornecedores de nutrientes (BUZINARO; BARBOSA,2009).

A diversidade microbiana no solo é bastante vasta, na qual é representada pela microfauna e microflora, que na sua composição está presente organismos procariontes, como bactérias, até mesmo os organismos eucariontes, na qual se destaca os fungos (CORRÊA; GALVÃO, 2010, p. 2). Esses organismos são os principias autores do ciclo de reciclagem de compostos orgânico e inorgânicos, segundo ARAÚJO e HUNGRIA (1994), dando estrutura na constituição dos solos, melhorando propriedades químicas e físicas destes. Porém, o mal manejo deste solo pode acarretar a diminuição da atividade microbiológica. O uso de agrotóxicos é um fator muito marcante na diminuição dos microrganismos, entretanto é a forma mais utilizada por agricultores para combater pragas e doenças, contudo estes acabam atingindo também ao equilíbrio do ecossistema microbiano.

CRUZ e ALVARENGA (2005), observam que práticas como o plantio direto é uma ótima alternativa de manejo para se ter um maior controle da preservação deste microrganismo na solução do solo. Outra pratica alternativa e muito eficiente é a incorporação de matéria orgânica no solo, que pode ser desde restos vegetais, como galhos, folhas e raiz ou até mesmo resto animais.

Desta forma o presente trabalho teve como objetivo geral, avaliar o solo em diferentes setores da Universidade do Oeste Paulista - Unoeste, no quesito qualidade, analisando a microbiologia do solo, determinando de modo geral qual deles seria o melhor para um bom desenvolvimento vegetal.

\section{MATERIAIS E MÉTODOS}

O experimento foi conduzido no laboratório de Microbiologia Agrícola da Universidade do Oeste Paulista (UNOESTE), Presidente Prudente - SP, durante os meses de fevereiro a maio de 2017. Foram coletadas amostras de solo no município de Presidente Prudente, os locais de análise foram: horta, cultura citros, cultura café, mata, cultura cana-de-açúcar, viveiro e cultura milho na propriedade da Universidade do Oeste Paulista.

Para quantificação de bactérias no solo foi realizada a técnica de diluição e plaqueamento, foi colocado $10 \mathrm{~g}$ da amostra no Erlenmeyer com $90 \mathrm{~mL}$ de solução salina estéril (sempre trabalhando próximo a chama), foi agitado a solução por dois minutos e repousou por mais de dois minutos, a diluição foi feita retirando, com auxilio de uma pipeta esterilizada, $1 \mathrm{~mL}$ da solução e transferiu-se para um tubo contendo $9 \mathrm{~mL}$ de solução salina. Repetiu-se os procedimentos para cada nova diluição, sempre pegando uma amostra de $1 \mathrm{~mL}$ da ultima solução preparada. Retirou-se $0,1 \mathrm{~mL}$ da solução com as diluições, logo após foi espalhado por toda superfície da paca de Agar utilizando a alça de Drisgalski, e por fim as placas foram levadas para encubar por 24 horas na temperatura de $32^{\circ} \mathrm{C}$.

A atividade da enzima desidrogenase foi feita com o objetivo de quantificar a presença de enzimas no solo, para essa etapa utilizou-se $5 \mathrm{~g}$ da amostra e adicionou-se $2 \mathrm{~mL}$ de solução T.T.C. $1 \%$ e também $1 \mathrm{~mL}$ de glicose $0,1 \%$. Em um tubo separado também foi utilizado $5 \mathrm{~g}$ da amostra, porém, foram adicionados $1 \mathrm{~mL}$ de glicose e $2 \mathrm{~mL}$ de tampão tris $0,1 \mathrm{M}$. Por fim agitou-se e foi 
encubado por 18 horas. Para efetuar a leitura adicionou-se $9 \mathrm{~mL}$ de Metanol nas amostras, foram agitadas e filtradas, e no espectrofotômetro foi feita a leitura em 530nm.

A medição do $\mathrm{CO} 2$ liberado serviu para quantificar a respiração do solo. Para isso pesou-se $50 \mathrm{~g}$ da amostra e foi colocado em um frasco hermético, dentro desse frasco, um Becker com $40 \mathrm{~mL}$ de Hidróxido de Sódio foi colocado sobre as $50 \mathrm{~g}$ de solo, em outro frasco foi preparado apenas com o Becker com a solução, os frascos foram encubados por 24 horas e foi feita a leitura com o condutivímetro. Para calcular o $\mathrm{CO} 2$ produzido utilizou-se a seguinte fórmula:

\section{Mg de CO2=22 x (CE do branco X CE da amostra) \\ CE do branco $-2,00$}

Para a extração do DNA do solo foi pesado $0,5 \mathrm{~g}$ da amostra e colocado em um tubo com 800uL de tampão, agitou-se e centrifugou - 5000rpm por 5 minutos, transferiu-se 700uL, foi agitado por 1 minuto e encubado por mais 10 minutos, acrescentou-se mais 300uL de Cloro/Issofoi agitado 1 minuto e centrifugado 12000rpm por 5 minutos, com ajuda de uma pipeta transferiuse $400 \mathrm{uL}$, acrescentou-se $450 \mathrm{uL}$ de Isopropanol $50 \mathrm{uL} \mathrm{de} \mathrm{NaCl}$, e foi centrifugado novamente. Após todo esse processo será descartado todo o sobrenadante por inversão e acrescentado 100uL de TE, por fim diluir por completo o "pillet" DNA e quantificar no espectrofotômetro.

\section{RESULTADOS}

Em relação a análise de números de bactérias, o solo retirado da horta teve o maior valor obtido, totalizando $6,0 \times 10^{6}$, (Fig. 1). Na respiração do solo, a horta também obteve o melhor resultado, totalizando 8,86 mg de $\mathrm{CO} 2$ por kg de solo, enquanto á área de cana-de-açúcar, obteve o menor valor: 4,04 mg de CO2 (Fig. 2).

A horta apresentou também os melhores desempenhos quanto á atividade enzimática no solo e quantificação de DNA extraído do solo (Fig. 3 e 4). Nestas avaliações as áreas de cultivo de citros e cana tiveram os piores resultados. Todos os resultados expostos foram agrupados em tabela para analise (Tabela 1).

Tabela 1. Resultado geral de diferentes análises dos diversos setores da Universidade do Oeste Paulista - Unoeste.

\begin{tabular}{ccccc}
\hline Setores & $\begin{array}{c}\text { No de bactérias } \\
\mathbf{1 0 ^ { 6 }}\end{array}$ & $\begin{array}{c}\text { Respiração do solo } \\
\mathbf{m g ~ d e ~ C O 2}\end{array}$ & $\begin{array}{c}\text { Desidrogenase } \\
\mathbf{n m}\end{array}$ & $\begin{array}{c}\text { DNA Total } \\
\mathbf{u g} / \mathbf{m l} \mathbf{1 0 ^ { 6 }}\end{array}$ \\
\hline $\begin{array}{c}\text { Horta } \\
\text { Citros }\end{array}$ & 6,0 & 8,86 & 604 & 429,3 \\
Café & 2,2 & 6,38 & 229 & 115,4 \\
Mata & 1,2 & 6,30 & 309 & 135,8 \\
Cana-de açúcar & 3,5 & 8,61 & 304 & 350,9 \\
Viveiro & 1,6 & 4,04 & 118 & 116,3 \\
Milho & 4,8 & 6,99 & 420 & 386,3 \\
\hline
\end{tabular}


Figura 1. Gráfico de quantidade de bactérias nas amostras de solos coletadas.

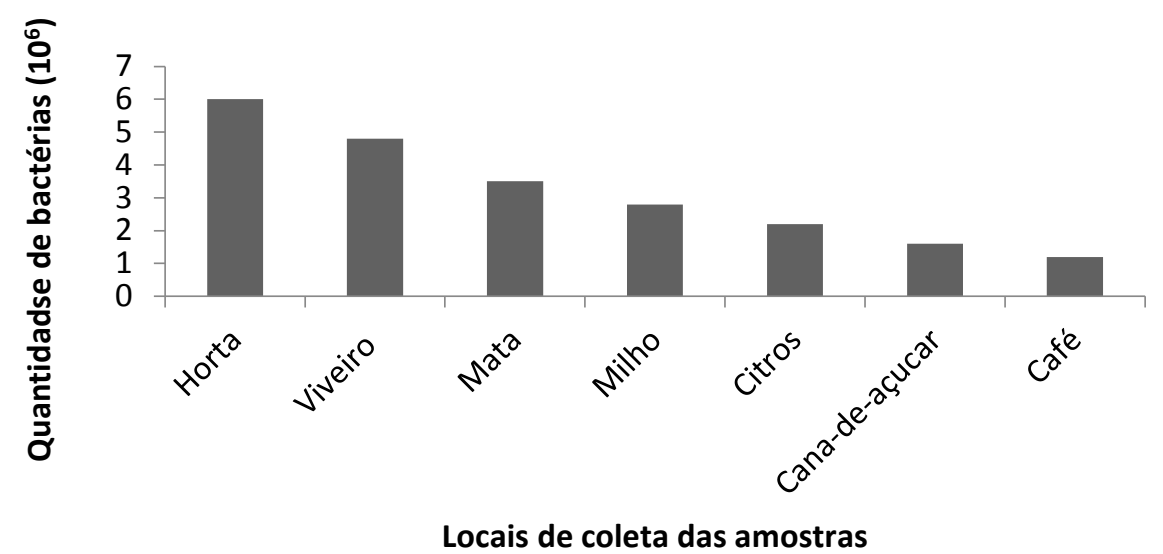

Figura 2. Gráfico da respiração do solo das amostras de solos coletadas.

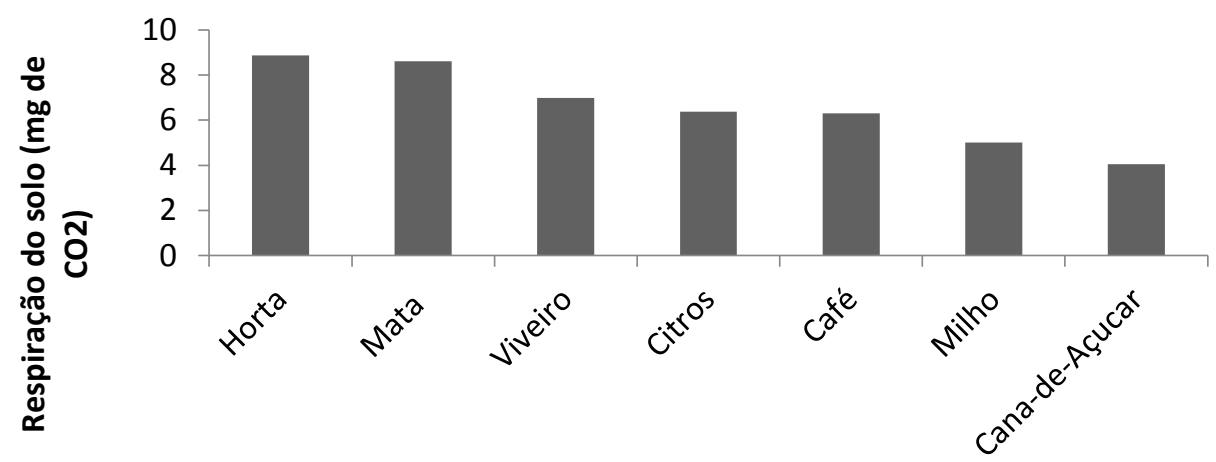

Locais de coleta das amostras

Figura 3. Gráfico da quantidade da enzima desidrogenase nas amostras de solos coletadas.

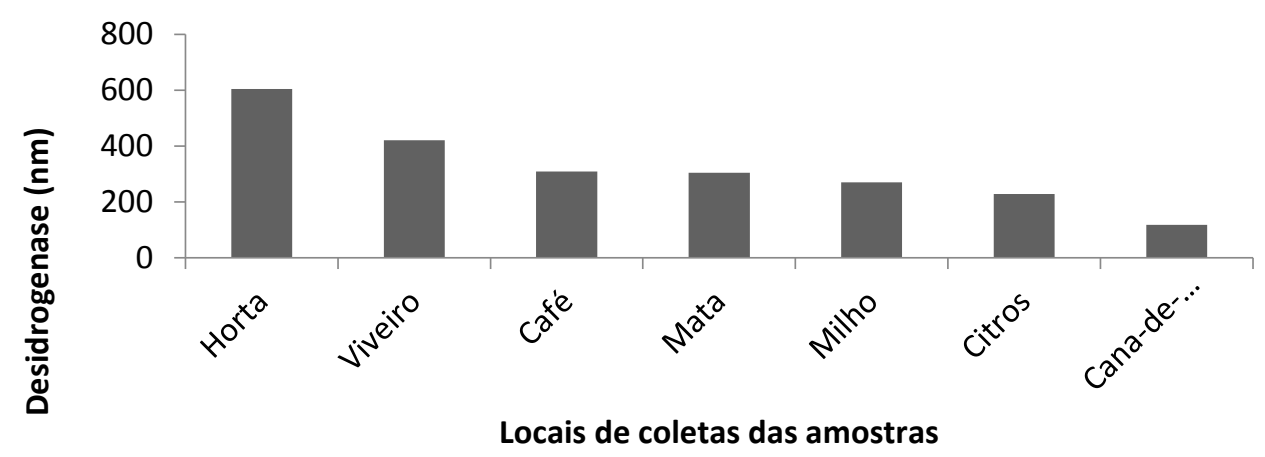


Figura 4. Gráfico da quantidade total de DNA nas amostras de solos coletadas.

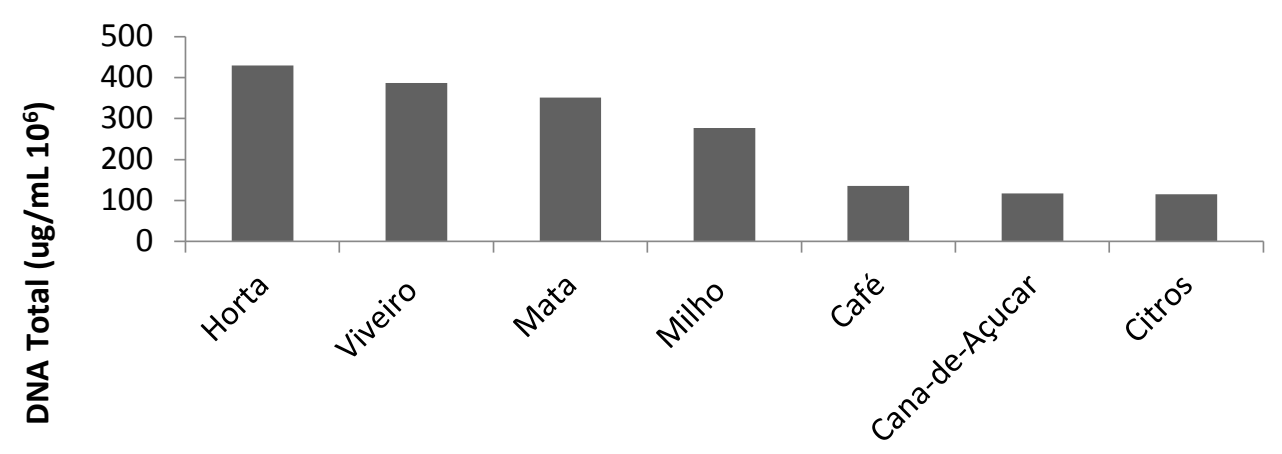

Locais de coletas das amostras

Com isto, nas condições deste estudo, pode-se enfatizar que solos sob manejos adequados terão uma boa atividade microbiana favorecendo diretamente na degradação da matéria orgânica, na transformação e disponibilidade dos nutrientes e na degradação de agrotóxicos no solo (STEFFAN et al. 2011). As variações nos resultados podem ser interpretadas e pré-avaliadas de acordo com as diferentes atividades que estão estabelecidas no local.

BRAGA, R.R et al. (2014) realizou um estudo que analisa a atividade microbiana no solo diante do controle de plantas daninhas no cultivo da mandioca com aplicação de herbicidas. No estudo ele demonstra que os microrganismos foram afetados diretamente pela ação dos herbicidas. Desta forma as monoculturas obtiveram resultados inferiores perante a atividade microbiológica, pois essas culturas recebem doses de herbicidas durante o seu cultivo.

A horta possui altos índices nos valores apresentados onde o manejo adequado e a pratica agrícola são fatores implantados para alcançar os melhores produtos, os outros pontos onde foram coletadas as amostras apresentam variações e se revezam entre os resultados baixos e intermediários, já que essas atividades necessitam de diferentes fatores e condições, além de serem culturas utilizadas experimentalmente pela Universidade do Oeste Paulista (UNOESTE), como no caso do viveiro, milho, citros, cana de açúcar e café,

A mata não recebe nenhum trato agrícola, porém, por ser uma área onde o acumulo de matéria orgânica por conta do conteúdo vegetativo ali depositado ser considerável, obteve resultados consideráveis nas análises, o maior deles é visto na análise de respiração do solo com 8,61 $\mathrm{mg}$ de CO2. Lourenço et al. (2003) estudaram a atividade microbiana em diferentes ecossistemas, como sistemas agroflorestais ( SAFs) avaliando taxas de respiração biológicas através da quantificação de $\mathrm{CO} 2$ no campo analisado, demonstrado que em áreas que com mata nativa a ação microbiológica é bem mais efetiva por sua alta taxa de composto orgânico.

\section{CONCLUSÃO}

Os resultados das análises mostraram que a horta e o viveiro obtiveram os melhores valores comparados com os cultivares de cana-de-açúcar e citros, sendo que, a mata e nos cultivos de milho e café obtiveram valores intermediários. Os índices demonstrados na horta e no viveiro sugerem que nesses locais houve melhores práticas de manejo do solo, consequentemente, apresentando uma alta qualidade para um bom desenvolvimento de planta.

\section{REFERÊNCIAS}

ARAÚJO, RICARDO S. E HUNGRIA, MARIANGELA. Microrganismo de importância agrícola. EMBRAPA-SPI, Brasília, DF. 1994, pg 7-8. 
BUZINARO, T. N.; BARBOSA, J. C.; Atividade microbiana no solo em pomar de laranja em resposta ao cultivo de adubo verde. Revista brasileira de fruticultura, v.31, n.2, Jaboticabal, SP, 2009.

CORRÊA, M. L. P.; GALVÃO, J. C. C.; FOTANETTI, A.; MIRANDA, G. V.; RODRIGUES, O. L. Avaliação microbiológica do sol em plantio de milho orgânico e convencional por meio da atividade enzimática, p 2, 2010. http://www.abms.org.br/cn milho/trabalhos/0136.pdf

CRUZ, J. C.; ALVARENGA, R. C.; VIANA, J. H. M.; Sistema de plantio direto de milho.EMBRAPA,2005.

http://webcache.googleusercontent.com/search?q=cache:kOvoQbUmiLUJ:www.agencia.cnptia.e mbrapa.br/gestor/milho/arvore/CONTAG01 72 59200523355.html+\&cd=1\&hl=pt-

$\underline{B R \& c t=c l n k \& g l=b r}$

ASSIS JÚNIOR, S.L.; ZANUNCIO, J.C.; KASUYA, M.C.M.; CAOUTO, L.; MELIDO, R.C.N. Atividade microbiana do solo em sistemas agroflorestais, monoculturas, mata natural e área desmatada. Sociedade de Investigações Florestais, v.27, n.1, p 35-41, Viçosa, MG, 2003.

BRAGA, R.R. et al. Atividade de microbiana do solo, controle de plantas daninhas e crescimento da mandioca após a aplicação de herbicidas. Bioscience Journal, v.30, n.4, p 1-9, 2014.

STEFFEN, G. P. K. et al. Contaminação do solo e da água por uso de agrotóxicos. Revista de Arquitetura e Ciências Agrarias, v.15, n.4, 2011. 